\title{
Nonlinear Discrete-Time Integral Sliding Mode Control of an Induction Motor: Real-Time Implementation
}

\author{
Asma CHIHI, Hechmi BEN AZZA, Mohamed JEMLI and Anis SELLAMI \\ Unit of research C3S, ENSIT, University of Tunis, 5 Av. Taha Hussein, BP 56, Tunis 1008, Tunisia. \\ asma.chihi@live.fr.
}

\begin{abstract}
This paper deals with a new design of discrete-time sliding mode control of an induction motor. Indeed, an integral switching surface is developed to ensure a high quality control with a short settling time and small zero steady state error. Besides, the integral tracking errors action improves the nonlinear system robustness and chattering reduction. Real-time experiments results are carried out using a dSpace system with DS1104 control board based on digital signal processor TMS320F240. To highlight the efficiency and applicability of the presented control scheme, a comparative study with other methods is given.
\end{abstract}

Keywords: Discrete-Time Integral Sliding Mode Control; Induction Motor; Digital Signal Processor (DSP); Switching Surface.

\section{Introduction}

Induction Motor (IM) admits a strongly nonlinear dynamic model. It constitutes an important research field for the synthesis of advanced control. The IM is characterized by a simple mechanical construction, better efficiency, low costs and robust model. Different control laws are developed for this type of system such as Field Oriented Control (FOC), Direct Torque Control (DTC), Fuzzy Logic Control (FLC), Neural Networks Control (NNC) and Sliding Mode Control (SMC) [1, 5, 12]. Specially, the latter is widespread in the last decades. This type of control is easy tuning and simple algorithm. As well, it is robust to parameter variations and uncertainties.

The sliding mode control is mainly used for different applications in continuous-time case $[6,11,19]$. However, the development of digital microprocessor technology creates the digital control systems. Despite the advantages which digital control provides, however their integration to control the IM of a little interest, because the sampled-time model of the IM presents a difficulty regardless sampling rates. Indeed, one can find only a few structures based on Euler method for Discrete-time Sliding Mode Control (DSMC) proposed in literature $[2,7,8]$.

Furuta proposed, in 1990, a DSMC for second order linear systems. In this approach, the chattering phenomenon is reduced and the system stability is proved using Lyapunov function [10].
Ortega and Taoutaou presented, in 1996, a discrete-time controller for current fed induction motor, [13]. In 1997, another discrete-time control for current fed IM was developed, [17]. Proca et al. studied, in [14], the advantages of DSMC algorithm using the equivalent control approach. Using the model presented in [13], a discrete time model was completed in [2] for voltage fed IM. This approach based on approximating the stator current dynamics used an explicit Euler method. In this method, the sliding surfaces are chosen as the error between the selected variable and its reference. The effectiveness of the applied control is shown only via simulations. The implementation of digital controller based on equivalent control approach was presented in [17]. In 2010, a modified version of Gao's reaching law is designed and implemented [18]. In [20], an active disturbance rejection control for IM is designed in discrete-time setting. Recently, in [8] Dominguez developed two discrete-time control schemes for IM using DSMC technique. The first controller is based on equivalent control method and the second one uses a discrete-time equivalent super twisting algorithm.

The aim of this paper is to design and implement a simple DSMC to an IM allowing high static and dynamic performances, in terms of perturbation rejection and tracking errors. Compared to the work presented in [8], the switching surfaces of the proposed DSMC law 
are designed by adding an integral action of the tracking errors.

This technique allows to reduce the torque oscillations and to ensure a high accuracy of control subject to parametric variations and uncertainties.

The stability of the proposed control law is investigated according to Lyapunov stability theory.

The paper is organized as follows: the problem statement is presented in section 2, where the control problem is developed. The DSMC is elaborated in section 3. Section 4 describes the stability analysis. Real-time implementation using dSpace DS1104 card based on real-time data acquisition control system, and experimental results are investigated in section 5. Finally, in order to demonstrate the performances of the proposed control, the discrete integral sliding mode of the tracking errors is compared to conventional discretetime Proportional Integral (PI).

\section{Problem Statement}

In [8], two discrete-time control schemes are proposed to drive the IM. In this work, Dominguez designed the first controller based on the discrete-time equivalent control method and the second controller used a discrete-time equivalent super twisting algorithm.

Figures 12 (a), 12(c), 14(a), 14(c), 16(a) and 16(c) show the real-time results of the rotor speed profile with sampling time equal to $250 \mu \mathrm{s}$, $750 \mu \mathrm{s}$ and $1250 \mu \mathrm{s}$, respectively [6]. Indeed, for a reference speed equal to $100 \mathrm{rad} / \mathrm{s}$, in all Figures 12-(a), 14-(a) and 16-(a), for $9 s \leq t<11 s$, the settling time is equal to $2 \mathrm{~s}$. Figures 12-(c), 14-(c) and 16-(c) show a considerable error between the rotor speed and the reference.

We remark that if the sampling time increases, the representative errors become important. Compared to the results presented above, in this work, we propose a simple discrete integral sliding mode control. The developed approach guarantees a good tracking speed and reduces torque oscillations with short settling time and zero steady state error using a sampling time equal to $250 \mu \mathrm{s}$.

The proposed Indirect Field Oriented Control (IFOC) is oriented along the d-axis. That means $\varphi_{r d}=\varphi_{r}$ and $\varphi_{r q}=0$. The discrete-time state space model equations of the induction motor

(IM) in (d-q) reference stationary frame is presented by the following system equations [15]:

$$
\begin{aligned}
i_{s d}(k+1) & =i_{s d}(k)-T e\left(\frac{1}{\sigma \tau_{s}}+\frac{1-\sigma}{\sigma \tau_{r}}\right) i_{s d}(k) \\
& +\frac{T e(1-\sigma)}{\sigma M_{s r} \tau_{r}} \varphi_{r d}(k) \\
& +\frac{T e(1-\sigma)}{\sigma M_{s r}} \varphi_{r q}(k) w(k) \\
& +\frac{T e}{\sigma L_{s}} V_{s d}(k)
\end{aligned}
$$

$$
\begin{aligned}
\varphi_{r q}(k+1) & =\varphi_{r q}(k)+T e \frac{M_{s r}}{\tau_{r}} i_{s q}(k) \\
& +w(k) \varphi_{r d}(k)-\frac{T e}{\tau_{r}} \varphi_{r q}(k)
\end{aligned}
$$

$$
\begin{aligned}
w(k+1) & =w(k)+T e \frac{3}{2} \frac{n p^{2}}{j} \frac{M_{s r}}{L_{r}}\left(\varphi_{r d}(k) i_{s q}(k)\right. \\
& \left.-\varphi_{r q}(k) i_{s d}(\mathrm{k})\right)-T e \frac{n p}{j}\left(C_{r}(k)-C_{f}(k)\right)
\end{aligned}
$$

$i_{s d}, i_{s q}=\quad \mathrm{d}-, \quad$ q-axis stator current components; $\varphi_{r d}, \varphi_{r q}=\mathrm{d}$-,q-axis rotor flux components; $V_{s d}, V_{s q}=\mathrm{d}$-,q-axis stator voltage components $; w_{r}, w_{d q}=$ rotor and synchronous angular speed ; $M_{s r}=$ cyclic mutual inductance stator-rotor ; $L_{s}, L_{r}=$ stator and rotor selfinductions ; $\tau_{s}, \tau_{r}=$ stator and rotor time constant; $\sigma=$ leakage coefficient ; $n p=$ 
pole-pair number $; j=$ inertia $; C_{f}=$ friction torque ; $C_{r}=$ load torque ; $T e=$ sampling time.

The parameters of the induction motor are listed in Table 1.

Table 1. Induction Motor Parameters

\begin{tabular}{|c|c|c|}
\hline Designation & Notations & $\begin{array}{l}\text { Rating } \\
\text { Values }\end{array}$ \\
\hline $\begin{array}{l}\text { Stator } \\
\text { resistance }\end{array}$ & $R_{s}$ & $2.3 \Omega$ \\
\hline $\begin{array}{l}\text { Rotor } \\
\text { resistance }\end{array}$ & $R_{r}$ & $1.83 \Omega$ \\
\hline $\begin{array}{l}\text { Stator self- } \\
\text { inductance }\end{array}$ & $L_{s}$ & $261 m H$ \\
\hline $\begin{array}{l}\text { Rotor self- } \\
\text { inductance }\end{array}$ & $L_{r}$ & $261 m H$ \\
\hline $\begin{array}{l}\text { Mutual } \\
\text { inductance }\end{array}$ & $M_{s r}$ & $245 \mathrm{mH}$ \\
\hline Inertia & $j$ & $0.03 \mathrm{kgm}^{2}$ \\
\hline $\begin{array}{l}\text { Friction } \\
\text { coefficient }\end{array}$ & $f$ & $0.002 \mathrm{Nm}$ \\
\hline $\begin{array}{c}\text { Pole-pair } \\
\text { number }\end{array}$ & $n p$ & 2 \\
\hline $\begin{array}{l}\text { Rated } \\
\text { power }\end{array}$ & $P_{n}$ & $3 k W$ \\
\hline $\begin{array}{l}\text { Rated } \\
\text { voltage }\end{array}$ & $V_{n}$ & $220 \mathrm{~V}$ \\
\hline
\end{tabular}

\section{Discrete-time Sliding Mode control Design}

In this section, the system is presented via an experimental test bloc, figure 1 . Indeed, the designed system is constituted by three phase IM (Unit 1) powered by an inverter (Unit 2). The IM is loaded by magnetic powder brake (Unit 3). The control strategy is implemented in real-time with a DS1104 controller Board (Unit 4 ), based on the interface control desk (Unit 5) in computer (Unit 6). The communication between the computer and the dSpace Microcontroller card is performed in real time with the communication protocol UART (Universal Asynchronous Receiver Transmitter), RS232, RS422 and RS485 $[9,16]$.
The control strategy is designed in discretetime form, based on the integral sliding mode technique. The latter is constituted by three control loops namely: speed controller, direct stator current controller and quadratic stator current controller, figure 2 .

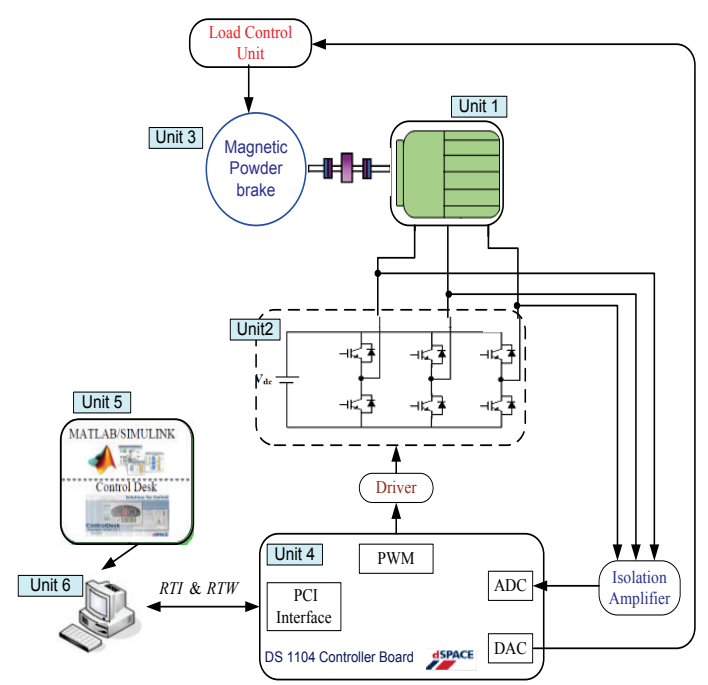

Figure 1. Bloc diagram of experimental Test system

The switching surfaces related to these controllers presented above are firstly designed in discrete-time with respect to the novel form. Then, the control law is secondly described.

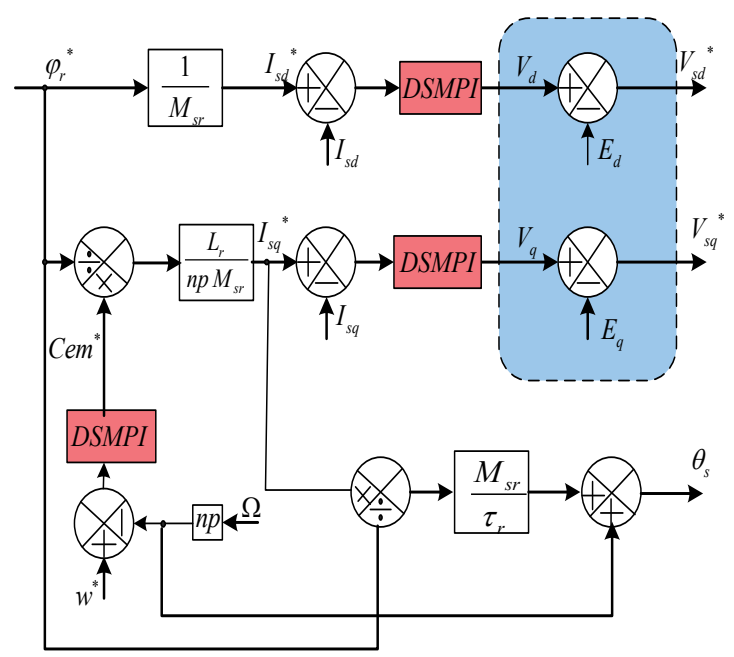

Figure 2. Discrete time sliding mode control

\subsection{Sliding Surfaces Design}

The selection of switching surface defining the representative control law can be described by:

$\begin{array}{lll}s_{w}=c_{1} \varepsilon_{w} & \text { with } & \varepsilon_{w}=w^{*}-w \\ s_{d}=c_{2} \varepsilon_{d} & \text { with } & \varepsilon_{\mathrm{d}}=i_{s d}{ }^{*}-i_{s d}\end{array}$ 
$s_{q}=c_{3} \varepsilon_{q} \quad$ with $\quad \varepsilon_{\mathrm{q}}=i_{s q}{ }^{*}-i_{s q}$

where

$\mathrm{c}_{1}, \mathrm{c}_{2}$ and $\mathrm{c}_{3}$ are positive gains.

To obtain a high performance system and a good tracking error, with zero steady state error and a fast response time, an integral action is added to the switching surfaces which can be expressed by:

$s_{w}=c_{1} \varepsilon_{w}+c_{4} \int \varepsilon_{w} d t$

$s_{d}=c_{2} \varepsilon_{d}+c_{5} \int \varepsilon_{d} d t$

$s_{q}=c_{3} \varepsilon_{q}+c_{6} \int \varepsilon_{q} d t$

with

$c_{4}, c_{5}$ and $c_{6}$ positive gains.

Referring to the Euler discretization technique, the Eqs. (9), (10) and (11) are written as:

$$
\begin{aligned}
\mathrm{s}_{w}(k+1)-s_{w}(k) & =\mathrm{c}_{1}\left(\varepsilon_{w}(k+1)\right. \\
& \left.-\varepsilon_{w}(k)\right)+T e \mathrm{c}_{4} \varepsilon_{w}(k) \\
\mathrm{s}_{d}(k+1)-s_{d}(k) & =\mathrm{c}_{2}\left(\varepsilon_{d}(k+1)-\varepsilon_{d}(k)\right) \\
+ & T e \mathrm{c}_{5} \varepsilon_{d}(k) \\
\mathrm{s}_{q}(k+1)-s_{q}(k) & =\mathrm{c}_{3}\left(\varepsilon_{q}(k+1)-\varepsilon_{q}(k)\right) \\
& +T e \mathrm{c}_{6} \varepsilon_{q}(k)
\end{aligned}
$$

Once the switching surfaces are selected for generating the global control, this involves the determination of control law related to each switching surfaces. It is necessary to determine the control for three controllers defined in figure 5 .

Referring to the definition of sliding mode, each control is presented by the sum of an equivalent component and a nonlinear one. For the following section, we detail the representative controllers.

\subsubsection{Speed Controller}

The time derivative of Eq. (9) is:

$$
\dot{\mathrm{S}}_{w}=\mathrm{c}_{1} \dot{\varepsilon}_{w}+\mathrm{c}_{4} \varepsilon_{w}
$$

The discrete-time switching surface relative to Eq. (15) is given by:

$$
\begin{aligned}
\mathrm{s}_{w}(k+1)-\mathrm{s}_{w}(k) & =\operatorname{Te}\left[\mathrm { c } _ { 1 } \left(\frac{\left(w^{*}(k+1)-w^{*}(k)\right)}{T e}\right.\right. \\
& \left.-\frac{(w(k+1)-w(k))}{T e}\right) \\
& \left.+\mathrm{c}_{4}\left(w^{*}(k)-w(k)\right)\right]
\end{aligned}
$$

It follows from Eq. (16) that:

$$
\begin{aligned}
\mathrm{s}_{w}(k+1)-\mathrm{s}_{w}(k) & =c_{1}\left(w^{*}(k+1)-w^{*}(k)\right) \\
& -(w(k+1)-w(k))) \\
& +\operatorname{Tec}_{4}\left(w^{*}(k)-w(k)\right)
\end{aligned}
$$

Subtituting Eq. (5) in Eq. (17), we get:

$$
\begin{aligned}
& \mathrm{s}_{w}(k+1)-\mathrm{s}_{w}(k)=c_{1} w^{*}(k+1)-c_{1} w^{*}(k) \\
& -c_{1} T e \frac{3}{2} \frac{n p^{2}}{j} \frac{M_{s r}}{L_{r}}\left(\varphi_{r d}(k) i_{s q}(k)\right) \\
& +c_{1} T e \frac{n p}{j}\left(C_{r}(k)-C_{f}(k)\right) \\
& +T e c_{4} w^{*}(k)-T e c_{4} w(k)
\end{aligned}
$$

The nonlinear control is presented by:

$$
\begin{aligned}
s_{w}(k+1)-s_{w}(k) & =-Q_{w} \operatorname{Te} s_{w}(k) \\
& -K_{w} \operatorname{Te} \operatorname{sign}\left(s_{w}(k)\right)
\end{aligned}
$$

where

$Q_{w}$ and $K_{w}$ are positive gains.

Imposing equality between the Eqs. (18) and (19), it leads to:

$$
\begin{aligned}
& c_{1} w^{*}(k+1)-c_{1} w^{*}(k) \\
& -c_{1} T e \frac{3}{2} \frac{n p^{2}}{j} \frac{M_{s r}}{L_{r}}\left(\varphi_{r d}(k) i_{s q}(k)\right) \\
& +c_{1} T e \frac{n p}{j}\left(C_{r}(k)-C_{f}(k)\right) \\
& +\operatorname{Tec}_{4} w^{*}(k)-\operatorname{Tec}_{4} w(k)= \\
& -Q_{w} \operatorname{Te~}_{w}(k)-K_{w} \operatorname{Tesign}\left(s_{w}(k)\right)
\end{aligned}
$$

So, the global control relative to the speed controller is defined by:

$$
\begin{aligned}
& i_{s q}(k)=\frac{2 j L_{r}}{3 c_{1} \operatorname{Tenp}^{2} M_{s r} \varphi_{r d}(k)} \\
& {\left[\begin{array}{l}
c_{1} w^{*}(k+1)-c_{1} w^{*}(k) \\
\left.+c_{1} \operatorname{Te} \frac{n p}{j}\left(C_{r}(k)-C_{f}(k)\right)\right] \\
+\operatorname{Tec}_{4} w^{*}(k)-\operatorname{Tec}_{4} w(k) \\
+Q_{w} \operatorname{Tes}_{w}(k)+K_{w} \operatorname{Tesign}\left(s_{w}(k)\right)
\end{array}\right]}
\end{aligned}
$$




\subsubsection{Direct Stator Current Controller}

The derivative of Eq. (10) is given as follows:

$\dot{s}_{d}=c_{2} \dot{\varepsilon}_{d}+c_{5} \varepsilon_{d}$

Basing on the Euler method, the Eq. (22) is given in the following form:

$$
\begin{aligned}
\mathrm{s}_{d}(k+1)-\mathrm{s}_{d}(k) & =T e\left[\mathrm { c } _ { 2 } \left(\frac{i_{s d}{ }^{*}(k+1)-i_{s d}{ }^{*}(k)}{T e}\right.\right. \\
& \left.-\frac{i_{s d}(k+1)-i_{s d}(k)}{T e}\right) \\
& \left.+\mathrm{c}_{5}\left(i_{s d}{ }^{*}(k)-i_{s d}(k)\right)\right]
\end{aligned}
$$

Replacing Eq. (1) in Eq. (23), we obtain:

$$
\begin{aligned}
& \mathrm{s}_{d}(k+1)-\mathrm{s}_{d}(k)=\mathrm{c}_{2} i_{s d}{ }^{*}(k+1)-\mathrm{c}_{2} i_{s d}{ }^{*}(k) \\
& -\mathrm{c}_{2}\left[\begin{array}{l}
-T e\left(\frac{1}{\sigma \tau_{s}}+\frac{1-\sigma}{\sigma \tau_{r}}\right) i_{s d}(k) \\
+\frac{T e(1-\sigma)}{\sigma M_{s r} \tau_{r}} \varphi_{r}(k)+\frac{T e}{\sigma L_{s}} V_{s d}(k)
\end{array}\right] \\
& +T e \mathrm{c}_{5} i_{s d}{ }^{*}(k)-T e \mathrm{c}_{5} i_{s d}(k)
\end{aligned}
$$

The nonlinear component is written as:

$$
\begin{array}{r}
s_{d}(k+1)-s_{d}(k)=-Q_{d} \operatorname{Tes}_{d}(k) \\
-K_{d} \operatorname{Te} \operatorname{sign}\left(s_{d}(k)\right)
\end{array}
$$

$Q_{d}$ and $K_{d}$ are positive gains.

The control relative to the direct stator current is determined by:

$$
V_{s d}(k)=\frac{\sigma L_{s}}{\mathrm{c}_{2} T e}\left[\begin{array}{l}
\mathrm{c}_{2} i_{s d}{ }^{*}(k+1)-\mathrm{c}_{2} i_{s d}{ }^{*}(k) \\
+\mathrm{c}_{2} T e\left(\frac{1}{\sigma \tau_{s}}+\frac{1-\sigma}{\sigma \tau_{r}}\right) i_{s d}(k) \\
-\mathrm{c}_{2} \frac{T e(1-\sigma)}{\sigma M_{s r} \tau_{r}} \varphi_{r}(k) \\
-\mathrm{c}_{2} \frac{T e}{\sigma L_{s}}+\mathrm{c}_{2} i_{s d}(k) \\
+T e \mathrm{c}_{5} i_{s d}{ }^{*}(k)-T e \mathrm{c}_{5} i_{s d}(k) \\
+Q_{d} T e s_{d}(k)+K_{d} \operatorname{Tesign}\left(s_{d}(k)\right)
\end{array}\right]
$$

\subsubsection{Quadratic Stator Current Controller}

The derivative representative equation defining the switching function relative to the quadratic stator current is expressed by:

$$
\dot{s}_{q}=c_{3} \dot{\varepsilon}_{q}+c_{6} \varepsilon_{q}
$$

The Euler discretization of Eq. (27) is as follows:

$$
\begin{aligned}
\mathrm{s}_{q}(k+1)-\mathrm{s}_{q}(k) & =\mathrm{c}_{3} i_{s q}{ }^{*}(k+1)-\mathrm{c}_{3} i_{s q}^{*}(k) \\
& -\mathrm{c}_{3} i_{s q}(k+1)+\mathrm{c}_{3} i_{s q}(k) \\
& +T e \mathrm{c}_{6} i_{s q}{ }^{*}(k)-T e \mathrm{c}_{6} i_{s q}(k)
\end{aligned}
$$

Using Eq. (2) in Eq. (28), we have:

$$
\begin{aligned}
\mathrm{s}_{q}(k+1)-\mathrm{s}_{q}(k)=\mathrm{c}_{3} i_{s q}{ }^{*}(k+1)-\mathrm{c}_{3} i_{s q}{ }^{*}(k) \\
-\mathrm{c}_{3}\left[\begin{array}{l}
-T e w_{d q} i_{s d}(k)-T e\left(\frac{1}{\sigma \tau_{s}}\right. \\
\left.+\frac{1-\sigma}{\sigma \tau_{r}}\right) i_{s q}(k) \\
-\frac{1-\sigma}{\sigma M_{s r}} w(k) \varphi_{r}(k)-\frac{T e}{\sigma L_{s}} V_{s q}(k)
\end{array}\right] \\
+\operatorname{Tec}_{6} i_{s q}{ }^{*}(k)-T e \mathrm{c}_{6} i_{s q}(k)
\end{aligned}
$$

The reaching law is given in representative form:

$$
\begin{aligned}
s_{q}(k+1)-s_{q}(k) & =-Q_{q} \operatorname{Te} s_{q}(k) \\
- & K_{q} \operatorname{Te} \operatorname{sign}\left(s_{q}(k)\right)
\end{aligned}
$$

$Q_{q}$ and $K_{q}$ are positive gains.

The global control is summarized as follows:

$$
V_{s q}(k)=\frac{\sigma L_{s}}{c_{3} T e}\left[\begin{array}{l}
-\mathrm{c}_{3} i_{s q}{ }^{*}(k+1)+\mathrm{c}_{3} i_{s q}{ }^{*}(k) \\
-\mathrm{c}_{3} T e w_{d q} i_{s d}(k) \\
-\mathrm{c}_{3} T e\left(\frac{1}{\sigma \tau_{s}}+\frac{1-\sigma}{\sigma \tau_{r}}\right) i_{s q}(k) \\
-\mathrm{c}_{3} \frac{1-\sigma}{\sigma M_{s r}} w(k) \varphi_{r}(k) \\
-T e \mathrm{c}_{6} i_{s q}^{*}(k) \\
+T e \mathrm{c}_{6} i_{s q}(k)+Q_{q} T e s_{q}(k) \\
+K_{q} \operatorname{Tesign}\left(s_{q}(k)\right)
\end{array}\right]
$$

\section{Stability Analysis}

In this section, let us consider the following Lyapunov function in order to involve the system stability [3, 4, 7]. We consider the relation $|u(k)| \leq u_{\text {max }}$, the control is defined by: 
$u(k)=\left\{\begin{array}{lll}u(k)_{\mathrm{eq}} & \text { for } & \left\|u(k)_{\mathrm{eq}}\right\| \leq u(k)_{\max } \\ \frac{u(k)_{\mathrm{eq}}}{\|u(k)\|} u(k)_{\max } & \text { for } & \left\|u(k)_{\mathrm{eq}}\right\|>u(k)_{\max }\end{array}\right.$

Wherein

$u(k)_{\mathrm{eq}}$ the equivalent control, $u(k)_{\max }$ a bound control and $\|$.$\| a vector norm.$

So, each controller developed above must be stable to ensure the system stability.

\section{Speed Controller}

Rewrite the equation (18) as follows:

$s_{w}(k+1)=s_{w}(k)+\mathrm{G}(k)+H(k) u(k)$

where

$$
\begin{aligned}
\mathrm{G}(k) & =c_{1} w^{*}(k+1)-c_{1} w^{*}(k) \\
& +c_{1} T e \frac{n p}{j}\left(C_{r}(k)-C_{f}(k)\right) \\
& +T e c_{4} w^{*}(k)-\operatorname{Tec}_{4} w(k)
\end{aligned}
$$

and

$$
H(k)=-c_{1} T e \frac{3}{2} \frac{n p^{2}}{j} \frac{M_{s r}}{L_{r}} \varphi_{r d}(k)
$$

Along any solution of Eq. (33), the increment of the Lyapunov function $\mathrm{V}(k)=\left\|s_{w}(k)\right\|$ is given by:

$$
\begin{aligned}
\Delta V(k) & =\left\|s_{w}(k+1)\right\|-\left\|s_{w}(k)\right\| \\
& =\left\|\left(s_{w}(k)+G(k)\right)\left(1-\frac{i_{s q(k)}}{i_{s q, \mathrm{eq}}}\right)\right\|-\left\|s_{w}(k)\right\| \\
& \leq\left\|s_{w}(k)+G(k)\right\|\left(1-\frac{i_{s q, \text { max }}}{\left\|i_{s q, \mathrm{eq}}\right\|}\right)-\left\|s_{w}(k)\right\| \\
& \leq\left\|s_{w}(k)+G(k)\right\|-H(k) i_{s q, \max }-\left\|s_{w}(k)\right\|
\end{aligned}
$$

The stability analysis is carried out under the following assumption:

(A.1) The value $u_{\max }$ is such as:

$$
u_{\max } \geq-\frac{1}{H(k)}\|G(k)\|(1+\varepsilon)
$$

for an $\varepsilon>0$, for all $w(k), \varphi(k)$ and for all admissible functions $w(k)$.

From the equations (36)-(39), we get:

$$
\begin{aligned}
& 0 \leq 1-\frac{i_{s q(k)}}{i_{s q, \mathrm{eq}}} \leq 1-\frac{i_{s q, \text { max }}}{\left\|i_{s q, \mathrm{eq}}\right\|} ; \\
& \text { where }\left\|i_{s q, \mathrm{eq}}\right\|=-\frac{1}{H(k)}\left\|s_{w}(k)+G(k)\right\|
\end{aligned}
$$

Under the assumption (A.1), it is possible to determine:

$$
\begin{aligned}
\left\|s_{w}(k)+G(k)\right\|-H(k) i_{s q, \max } & \leq\left\|s_{w}(k)\right\| \\
& -\varepsilon\|G(k)\|<\left\|S_{w}(k)\right\|
\end{aligned}
$$

After the condition (42), when $\left\|s_{w}(k)\right\|$ decreases monotonically, the $\left\|i_{s q \text {,eq }}\right\|$ decreases monotonically. It exists an instant $k_{1}$ that $\left\|i_{s q, \mathrm{eq}}\right\| \leq i_{s q, \max }$ for all $k \geq k_{1}$.

The same stability analysis is given for the direct and quadratic current controller.

\section{Real-time Implementation and Experimental Results}

The effectiveness of the proposed Discrete-time Integral Sliding Mode Control (DISMC) of the IM was implemented using MATLAB/ Simulink and dSpace DS1104 real-time controller board. This one integrates a MOTOROLA Power PC603e model, and digital signal processing (TMS320F240-20 $\mathrm{MHz}$ ). The experimental platform was shown in figure 3. It is made of three parts:

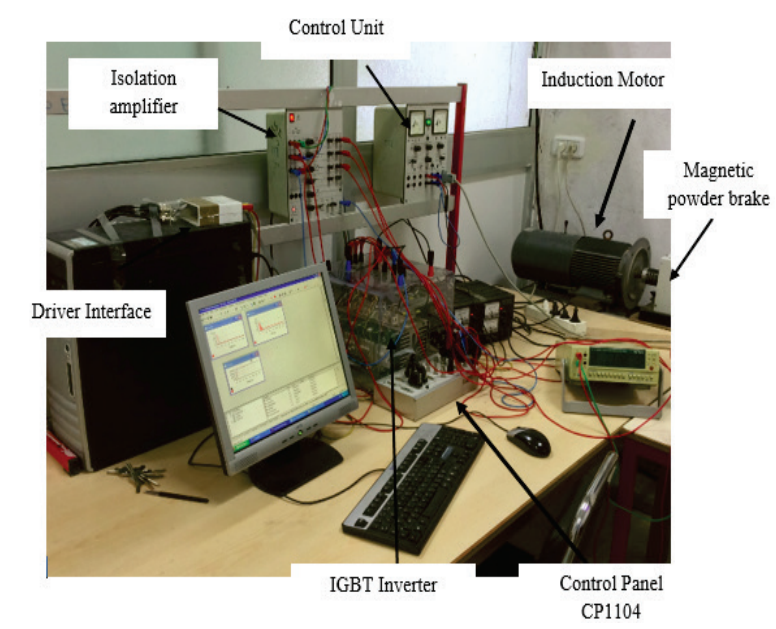

Figure 3. Experimental Test System

- An inverter with an architecture based on a SEMIKRON IGBT.

- A three phase IM loaded by a magnetic powder brake.

- A control algorithm is implemented in realtime dSpace card DS1104.

The Pulse Width Modulation (PWM) technique presented a sinusoidal form with a switching frequency equal to $3 \mathrm{kHz}$ and a dead time of $2 \mu$ s for the three level inverter. 


\subsection{Experimental Results of DISMC}

To validate the effectiveness of the proposed DISMC, experimental test system is performed with a nominal reference rotor flux equal to $0.8 \mathrm{~Wb}$.

The reference speed starts in $0 \mathrm{r} / \mathrm{min}$ for $0 s \leq t<1 s$, and it increases to $1500 \mathrm{r} / \mathrm{min}$ for $1 s \leq t<15 s$.

The load torque starts with $0 \mathrm{Nm}$ for $0 s \leq t<4.5 s$. Then, at $10 \mathrm{Nm}$ for $4.5 s \leq t<10 s$ and comes back $0 \mathrm{Nm}$ for $10 s \leq t<15 s$.

Figure 4 presents the rotor speed profile using a sampling period $250 \mu \mathrm{s}$. Figure 5 shows the zoom. The latter illustrates a good tracking with the reference especially in the insertion of the load torque. This allows a good tracking performance due to the addition of integral action with a fast response time equal to $0.8 \mathrm{~s}$ and without overshoot.

Figure 6 illustrates the electromagnetic torque profile. It starts without overshoot and with a minimal reduction chattering, the zoom is in figure 7 .It is clear that the proposed controller reached the desired reference in a finite time and eliminated the disturbance with minimal oscillations.

Figures 8, 9 and 10 show respectively the three switching surfaces related to the three controllers such as speed controller, direct stator current controller and quadratic stator current controller. It's clear that each characteristic converges to zero with minimal peak start up. This proves the criteria of sliding mode.

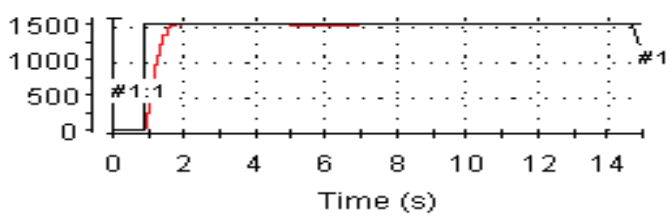

\#1:1 Real speed (rpm)

\#1:2 Reference speed (rpm)

Figure 4. Rotor Speed Profile

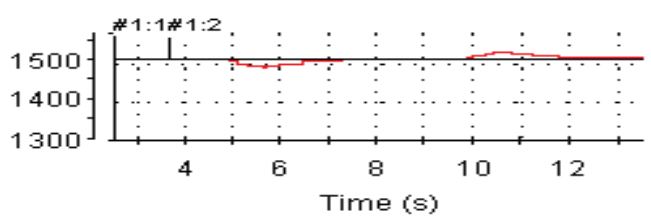

W1:1 Real speed (rpm)

W1:2 Reference speed (rpm)

Figure 5. Zoom of the rotor speed

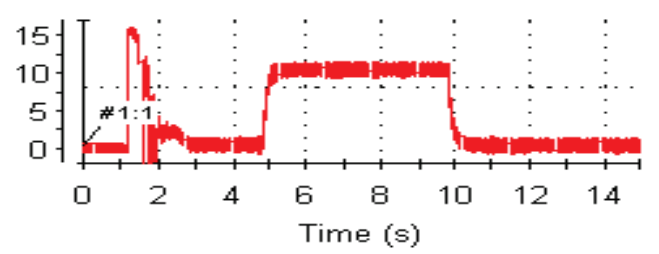

W1:1 Electromagnetic torque (Nm)

Figure 6. Electromagnetic torque profile

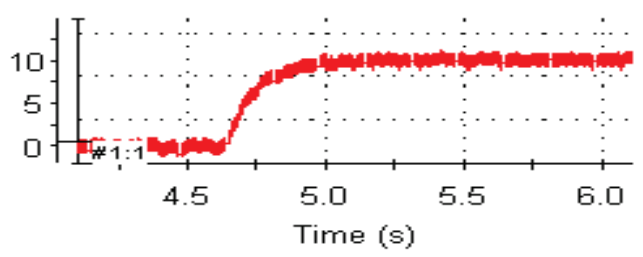

W1:1 Electromagnetic torque (Nm)

Figure 7. Zoom of the electromagnetic torque

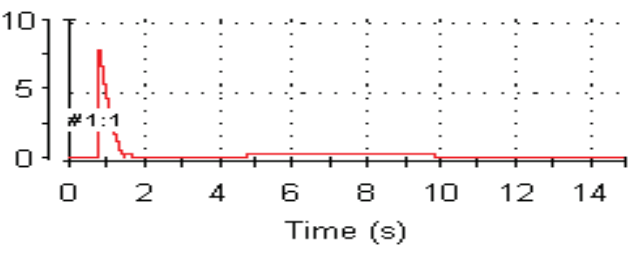

\#1:1 Switching surface (swi)

Figure 8. Switching surfaces $s_{w}$ relative the speed controller

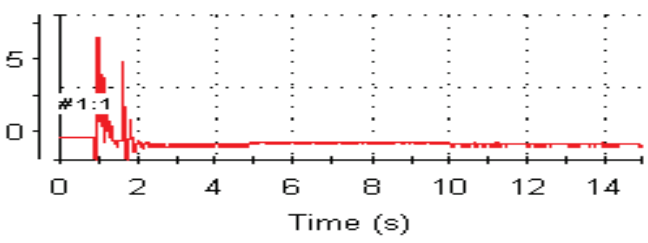

\#1:1 Swuitching surface (sd)

Figure 9. Switching surfaces $s_{d}$ relative the speed controller

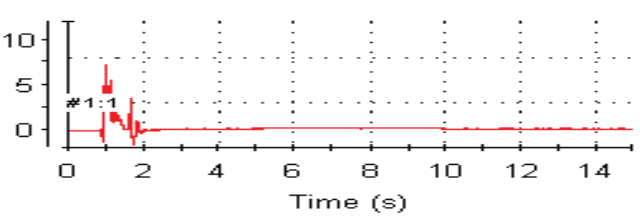

Figure 10. Switching surfaces $s_{q}$ relative the speed controller

\subsection{Comparative Study}

In order to show the advantages and the effectiveness of the proposed approach compared to other control techniques, we compare the Integral DSMC with firstly discrete-time conventional Proportional Integral (PI) and secondly with the approach presented above in Section 2. 


\subsubsection{Comparison of the proposed approach with discrete-time conventional PI.}

Comparing the found results with other control techniques applied to the same studied system, we modify the three discrete-time sliding mode controller by three discrete-time conventional Proportional Integral (PI).

Figures 11 and 12 show experimental results for both the electromagnetic torque and the rotor speed responses with discrete-time conventional PI technique. These Figures are tuned in the same test conditions presented by our approach. The load torque starts with $0 \mathrm{Nm}$ for $0 s \leq t<6 s$ then, at $10 \mathrm{Nm}$ for $6 s \leq t<12 s$ and comes back $0 \mathrm{Nm}$ for $12 s \leq t<15 s$.

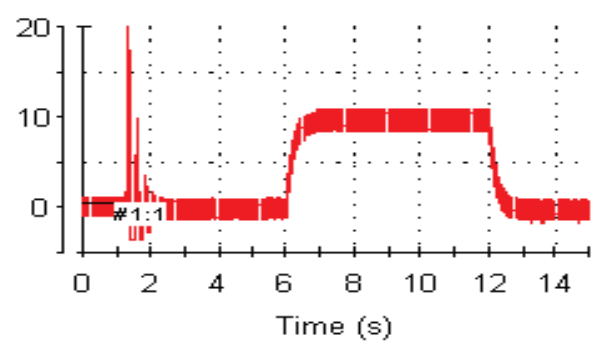

\#1:1 Electromagnetic torque $(\mathrm{Nm})$

Figure 11. Electromagnetic torque profiles with conventional PI

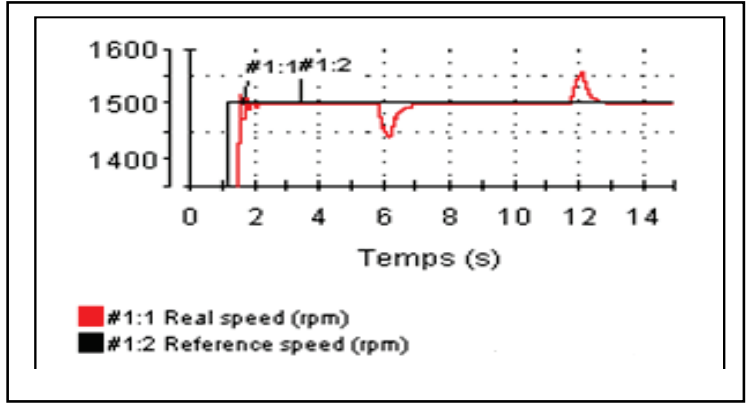

Figure 12. Rotor speed profiles with conventional PI

Figure 11 represents the variation of the electromagnetic torque. It's clear that the use of the classical PI introduces a considerable chattering. Also, the torque starts with a peak equal to $20 \mathrm{Nm}$. However, in our method the chattering was reduced and the peak start-up is $15 \mathrm{Nm}$. The torque oscillations have an influence on the waveform of the speed, figure 12. It represents an oscillation in $1 \mathrm{~s}$. With the insertion of the load torque, the speed profile decreases about $50 \mathrm{rad} / \mathrm{s}$, but in our method it decreases about $15 \mathrm{rad} / \mathrm{s}$.

The effectiveness of the proposed integral sliding mode in terms of chattering reduction, robustness and nominal steady state error are experimentally validated, table 2 .

Table 2. Comparison of the proposed integral DSMC with the PI control Technique

\begin{tabular}{|l|c|c|}
\cline { 2 - 3 } \multicolumn{1}{c|}{} & DISMC & $\begin{array}{c}\text { Discrete-time } \\
\text { conventional PI }\end{array}$ \\
\hline Tracking & Very good & Good \\
\hline Chattering (torque) & $2 N m$ & $5 \mathrm{Nm}$ \\
\hline Chattering (speed) & Without & Considerable \\
\hline Settling time (speed) & $0.8 s$ & $1.1 s$ \\
\hline Settling time (torque) & $0.2 s$ & $0.8 s$ \\
\hline Overshoot (speed) & $<1 \%$ & $<4 \%$ \\
\hline Peak start-up (torque) & $15 \mathrm{Nm}$ & $20 \mathrm{Nm}$ \\
\hline Peak start-up (speed) & Without & $<3 \%$ \\
\hline
\end{tabular}

\subsubsection{Comparison of the proposed approach with the control law developed by Rivera}

Compared to the results presented in [6], especially for the rotor speed, the proposed discrete integral sliding mode technique presents the following advantages:
- Simple.

- Admits a fast response: the rise time is $0.6 \mathrm{~s}$.

- Good settling time equal to $0.8 \mathrm{~s}$.

This confirms the effectiveness of the integral DSMC using the integral of tracking errors, table 3. 
Table 3. Camparison of the proposed integral DSMC with the approach presented in [6]

\begin{tabular}{|c|c|c|}
\cline { 2 - 3 } \multicolumn{1}{c|}{} & Our Approach & $\begin{array}{c}\text { Approach presented in } \\
{[\mathbf{6}]}\end{array}$ \\
\hline Dynamic response & Good & Good \\
\hline complexity & Simple (One control) & High (Two control) \\
\hline Robustness & Good & Good \\
\hline Settling time & $0.8 s$ & $2 s$ \\
\hline Rise time & $0.6 s$ & $1.8 s$ \\
\hline
\end{tabular}

\section{Conclusion}

In this work, the designed control is developed by using an integral discrete-time sliding mode technique, based on tracking errors and Lyapunov stability analysis. Indeed, the discretization of the control system is based on Euler method. Besides, the proposed discretetime integral sliding mode control is a simple modelling control compared to the work presented by Dominguez. Also, the considered control law was compared with discrete-time conventional PI.

Real-time results showed that the discrete integral sliding mode still performs better than other approaches such as Dominguez control law and conventional PI. Indeed, integral DSMC technique presents a fast response, a good tracking error regardless disturbances and a reduction to chattering.

\section{REFERENCES}

1. Akin, B. \& Bhardwaj, M. (2013). Sensored Field Oriented Control of 3-Phase Induction Motors, Texas Instruments, pp. 1-35.

2. Castillo, T. B., Di Gennaro S., Loukianov, A. G. \& Rivera, J. (2008). Discrete time Sliding Mode Control with Application to Induction Motors, Automatica, 44 (2008), pp. 3036-3045.

3. Castillo, T. B., Di Gennaro, S., Loukianov, A. G. \& Rivera, J. (2004). On The Discrete-time Modelling and Control of Induction Motors with Sliding Modes, Proceedings of the 2004 American Control Conference, pp. 2598-2602.
4. Castillo, T. B., Di Gennaro, S., Galicia, M. I., Loukianov, A. G. \& Rivera, J. (2010). Indirect Discrete-time Sliding Mode Torque Control of Induction Motors, XIX InternationalConference on Electrical Machines (ICEM), pp. 1-6.

5. Chihi, A., Chbeb, A. \& Sellami, A. (2015). Switching Function Optimization of Sliding Mode Control to Photovoltaic Pumping System, Advances and Applications in Sliding Mode Control Systems, 576, pp. 463-493.

6. Chihi, A., Sellami, A., Khalfa, M. A. (2012). Sliding Mode Control of a Photovoltaic Pumping System, Mediterranean Elecrotechnical Conference (MELECON), pp. 936-939.

7. Chihi, A. \& Sellami, A. (2016). Nonlinear Discrete Time Sliding Mode Control Applied to Pumping System, Advances and Applications in Nonlinear Control Systems, 635, pp. 595-609.

8. Dominguez, J. R. (2015). Discrete time Modelling and Control of Induction Motors by Means of Variational Integrators and Sliding Modes-Part II: Control Design, IEEE Transactions on Industrial Electronics, 62(10), pp. 6183-6193.

9. Furuta, K. \& Morisada, M. (1988). Implementation of Sliding Mode Control by a Digital Computer, 14 Annual Conference of Industrial Electronics Society IECON'88, pp. 453-458.

10. Furute, K. (1990). Sliding Mode Control of a Discrete System, Systems \& Control Letters, 14(2), pp. 145-152. 
11. Jawad, S. A., Iqbal, J., Khan, A. A. \& Mehmood, A. (2015). DisturbanceObserver-Based Robust Control of a Seriallink Robotic Manipulator using SMC and PBC Techniques, Studies in Informatics and Control, 24(4), pp. 401-408. Maraba, A. \& Kuzucuoglu, A. E. (2011). Speed Control of an Asynchronous Motor using PID Neural Networks, Studies in Informatics and Control,20(3), pp. 199-209.

12. Ortega, R. \& Taoutaou, D. (1996). A Globally Stable Discrete-Time Controller for Current Fed Induction Motors, Systems \& Control Letters, 28(3), pp. 123-128.

13. Proca, A., Keyhani, A., Utkin, V. \& Miller, J. (2002). Discrete Time Sliding Mode, Continuous Time Sliding Mode and Vector Control of Induction Motors, International Journal of Control, 75(12), pp. 901-909.

14. Robyns, B., Francois, B., Degobrt, P. \& Hautier, J. P. (2012). Vector Control of Induction Machines, Desensitisation and Optimisation through Fuzzy Logic, XXVI-222.
15. Skender, M. R. \& Telmcani, A. (2016). Implementation of a New Ssuper Twisting Mode Algorithm Controlled by dSpace: Application to Series Multicell converter, Studies in Informatics and Control, 25(2), pp. 255-264.

16. Taoutaou, D., Puerto, R., Ortega, R. \& Loron L. (1997). A New Field-Oriented Discrete Time Controller for Current Fed Induction Motors, Control Engineering Practice, 5(2), pp. 209-217.

17. Veselic, B., Drazenovic, B. P. \& Milosavljevic, C. (2010). Improved Discrete Time Sliding Mode Position Control Using Euler Velocity Estimation, IEEE Transactions on Industrial Electronics, 57(11), pp. 3840-3847.

18. Wang, H., Zhang, W., Tian, Y. \& Qu, Q. (2015). Sliding Mode Control for Diesel Engine using Extended State Observer, Studies in Informatics and Control, 24(4), pp. 439-448.

19. Wu, M. \& Chen, J. S. (2014). A DiscreteTime Global Quasi-Sliding Mode Control Scheme with Bounded External Disturbance Rejection, Asian Journal of Control, 16(6), pp. 1-10. 